\title{
Environmental Management Challenges and Possible Solutions Regarding Chemical Pollution Caused by Households in Latvia: A Qualitative Pilot Study
}

\author{
Lāsma AKŪLOVA ${ }^{1 *}$, Anna BUKINA ${ }^{2}$, Žanna MARTINSONE ${ }^{3}$ \\ ${ }^{1-3}$ Institute for Occupational Safety and Environmental Health, Rīga Stradiňš University, \\ Dzirciema iela 16, Riga, Latvia
}

\begin{abstract}
The aim of this study was to determine public perception of chemical pollution and environmental management problems in Riga, Latvia, and obtain possible solutions to these problems. This is a qualitative study where data was obtained by organizing focus group interviews. A total of 3 focus groups were held with 18 participants taking part. The first focus group consisted of adults living in apartments, the second group - of adults living in houses, and the third group consisted of students; all respondents live in Riga city or its peri-urban area. The results have shown that the main problems defined by respondents regarding chemicals and environmental management is lack of information, low level of environmental education, complexity of available information on chemicals and environmental aspects, inappropriate infrastructure and lack of availability of environmental services. The potential solutions for determined problems are qualitative environmental education in schools, improved informative material accessibility by creating applications for smartphones, advertisement and social campaigns, ensuring provision of infrastructure and services, and implementation of packaging deposit system.
\end{abstract}

Keywords - Attitudes; environmental governance; environmental education; infrastructure; waste management; waste sorting

\section{INTRODUCTION}

Nowadays humans face environmental problems that have slowly and steadily developed in the previous generations. It is clear that this century must mark the turning point in the ways that society has lived before. Society must learn how to live more sustainably in order to re-new and preserve its own life support system - the environment [1]. The shift has already begun - the latest EuroBarometer on Climate change shows that climate change is seen as the single most serious problem facing the world today and it is the first time that citizens have expressed that climate change should be top priority for European Parliament [2].

Pollution is strongly linked to human population: the growing number of people puts a huge strain on the environment - people consume vast amounts of food, water, energy, creating pollution. Pollution prevention is more cost-effective and environmentally friendly than dealing with the consequences and cleaning up. More than a decade has passed since the introduction of REACH (Registration, Evaluation and Authorisation of and Restriction Chemicals Regulation) in 2007 and CLP (the Regulation on the Classification, Labelling and

* Corresponding author.

E-mail address: Lasma.Akulova@rsu.lv 
Packaging of substances and mixtures) in 2009 and it is believed that it has improved consumer confidence in chemicals use meaning that more EU citizens feel that in the last 10or 15-years chemical safety has improved [3].

Anthropogenic chemical pollution impacts the environment by unsafe use and management of chemicals. Since most of the chemical pollution is man-made, prevention of it would be to address the main source - humans [4], and this is where environmental management plays a significant role. Through the systems of environmental management it is possible to change the pace of environmental pollution by approaching environmental challenges with "focusing on environmental regulations and standards, and customer requirements. It is based on the need to respond proactively to the management of natural environment by conducting lifecycle assessment to lessen environmental burden and optimize the use of limited natural resources". [5]. Environmental management aims to manage the impacts of everyday life on environment and strives to lessen environmental degradation. Management consists of many subthemes; however, it starts from society and its defined environmental objectives represented by governments and regulators. The impact of society opinion is crucial in understanding ways for policy makers to address the environmental issues of today [6].

Households as major contributors to chemical pollution have emerged as a problem during previous projects and studies in Europe [7]-[9] showing that households excerpt a vast majority of harmful substances through waste waters [8] and actions like cooking, heating, usage of personal care products and cleaning agents [10]. Waste, if not recycled, can pollute the environment as well, therefore research, for example, unsorted municipal waste analysis to determine its content for future waste management system improvements in this area is present [11]. The study concluded that total waste amount correlates with number of inhabitants, however, waste composition is influenced by other factors such as local system of waste management.

This issue is important both at regional and European levels - chemical pollution health impact and possibilities to lessen it has been a top priority for Horizon2020 Programme HBM4EU [12]. A recently carried-out project involving 9 Baltic Sea Region municipalities concluded that municipalities are key players in pollution reduction, because they can set strategic and tailored goals [13]. As a result of this project the municipality of Riga developed a strategy called Chemical Action Plan (CAP) for 2019-2024 including activities for raising public awareness on household chemical pollution [14].

The issue of pollution seeks for solutions and this study aimed to explore the starting point of it - citizens of households of Riga and its peri-urban area. To date no known qualitative research has been made to gather in-depth information as to why citizens of Riga find it hard to make environmentally friendly decisions and take sustainable actions and what are the solutions to these problems (in their opinion). The aim of this pilot study is to determine public perception of chemical pollution and environmental management problems in Riga, Latvia, and obtain solutions to these problems. It also aims to explore the information gaps so that guidelines and recommendations could be given to authorities for future project planning.

\section{Methods ANd Methodology}

Qualitative research offers in-depth opinions to describe the respondents' point of view [15]. Purposive sampling technique was used to select participants for this study. The primary data source were individuals living in Riga and its peri-urban area. Riga, as the capital city, has the largest urban area in Latvia. The individuals had to be at least 18 years old and 
not exceed the age of 64 , so they would still be part of the active population. The participants had to be at least students enrolled in higher education institution since age and education level has an impact on one`s environmental awareness [2], [16], [17].

A convenience sampling method was used to gather respondents, meaning that information about taking part in a focus group was spread via social channels (colleagues' and friends' resources as well as social platforms such as Facebook and Instagram) for individuals living in apartments or houses in Riga or its peri-urban area. Those that agreed were asked to come for the interview in Rīga Stradiņš University settings, but the student group was drawn together using workspace as a source - an office in Riga's peri-urban area offered to hold the focus group at their setting for their convenience and the interviewer did the interview there.

The study model of using focus group interviews for in-depth information about household chemical pollution was mostly taken from a Horizon 2020 co-funded effort of 30 countries, the European Environment Agency and the European Commission, called "HBM4EU". Rīga Stradiņš universities Institute for Occupational Safety and Environmental Health is one of the partners included in this programme and therefore has access to study protocols and reports (not publicly available). In one of these studies carried out in Austria, a similar approach was chosen, concluding a focus group of 14 respondents whose responses were then analysed and used for informing policy makers to improve the protection of European citizens' health from chemical exposure [12].

Three focus group interviews were conducted for data collection within this qualitative research. Two focus groups consisted of adults living either in apartments $(N=8)$ or houses $(N=5)$ within Riga city or Riga peri-urban area. The third focus group was conducted in an office setting, consisting of students living in Riga $(N=5)$. All focus group interviews were conducted in October - November 2019. Each interview lasted no more than 90 minutes and the interviewer followed an interview guide consisting of open-ended questions regarding their opinions on chemical pollution, the ways their housing attributes to it; waste management; environmental information availability and health effects of environmental pollution. A total of 18 participants were interviewed in the focus groups, 9 women and 9 men, respectively with age ranging from 19 to 52. Although the size of the study group is 18 respondents, research shows that in qualitative research studies as little as 12 respondents can be enough when no important opinions arise and meet the "thematic saturation" [18].

This study was approved by the Ethics Committee of Rīga Stradiņš University. Informed written consents were obtained from participants prior data collection. The interviews were tape-recorded, then transcribed and analysed using thematic analysis.

\section{Results}

This section summarizes the results of focus group interviews describing respondents opinions on problems they identified regarding environmental pollution and environmental management topics followed by their proposed solutions to improve the situation. The main problems identified by respondents were lack of information and environmental education, infrastructure provision and access to the services, responsibility and environmental management. The identified issues are described in the following sub-sections. At the same time, it should be taken into account that no evaluation of indoor air pollution was made in this study. 


\subsection{The Lack of Information and Environmental Education}

The biggest part of research participants noted that the lack of information and environmental education, as well as complexity of available information were the main problems that determined their own actions and actions of other inhabitants of Riga. The lack of information and environmental education were mentioned while talking about hazardous waste management (drugs, asbestos slate, paints and varnishes, waste oils, tires, light bulbs), large garbage management, preparation of used packaging for waste recycling bins and waste sorting aspects, the meaning of the chemical products labelling and other topics. The participants of two focus groups (individuals living in apartments and individuals living in houses) mentioned lack of information in the society, whereas participants of the third focus group (students) expressed their own lack of knowledge about described environmental aspects.

Respondents noted that information about environmental topics and chemicals they are interested in is often complicated and difficult to understand. They believe that in order to understand it, they must seek for special motivation because the search for it is too time consuming and difficult.

- On waste preparation for waste recycling bins: "You can certainly find resources in the Internet, where (it) is described - if there is this triangle, this number - it means this is washable or not. But this information is not easy to understand. (...) But about searching of information. The defined situation - I am interested in what should I do with an exact piece of plastics. I can't search "the triangle with the five in the centre", this won't bring me any good result."

- On information: "We need everything to be fast. We are used to fast information."

- On labelling: "About the same labelling. Tell me, what these substances are. I am not going to read this European long list (of chemicals), because if I do, I won't have any time to work, earn money or anything else".

\subsection{Inaccessible Infrastructure and Access to the Services}

Regarding decision making related to the chemicals and environment, focus group participants mentioned the importance of cost, infrastructure provision, availability of the service, functionality and effectiveness, simplicity, example, ecological safety and origin. It was also mentioned that the existing infrastructure and service availability is one of the most important factors that determines their actions.

The importance of infrastructure and service availability was mentioned by respondents in relation to large garbage management, tire management, old clothing management, and connection to the centralized networks, invalid electrical equipment and battery management, particularly in relation to the waste recycling aspects. Infrastructure and service availability were mostly mentioned in negative aspect - the lack of infrastructure or service was noted as the main factor for not recycling their waste:

"I don't sort waste because there is no place besides my house where anyone can hand over sorted waste. Because I just don't want to go to the nearest container for 10 minutes."

"I don't sort because I live in the house and we get every two weeks a car to collect our garbage. And it wasn't offered to install specialized containers for waste sorting. This is the only reason why I am not sorting waste." 
It must be mentioned that respondents in all focus groups expressed a positive attitude towards existing infrastructure of used battery collection.

\subsection{Suggested Solutions for the Lack of Information and Environmental Education}

Participants of focus groups shared their thoughts on ways to improve the identified problems and offered possible solutions. Solutions for the improvement of public environmental knowledge and access to information are improved environmental education in schools, informative materials, and relevant applications for smartphones, advertisement and social campaigns. Each of these proposed solutions are described below.

\subsubsection{Environmental education in schools.}

The schools' impact on the level of environmental education of children and their parents was mentioned by respondents who have school-aged children. The respondents mentioned that they had a positive experience with environmental education at their children's schools. The competitions between school classes and lessons on the importance of waste sorting as well as proper hazardous waste (battery) management were seen as positive. Usually these activities get the whole family involved in various types of events and competitions and as a result not only the children but also their families learn about important environmental topics. Therefore, the improvement of environmental education in schools could improve understanding of environmental issues and promote environmental awareness in families and society overall.

One of the participants expressed an opinion regarding environmental education in schools:

"I would say that it has to be brought up in the generations. What schools do is the way how families are immediately influenced. If your child asks: "Mom, why don't you sort the garbage?", then... I think, that is a lot, because, let's be honest, it's difficult to reteach people. I think a lot in our society comes in with generation change".

\subsubsection{Informative materials.}

Informative materials are seen as a good way for society education. To make the informative material useful it should be placed in a suitable location, it must be easy to find, and it should contain a concise but comprehensive and clear information.

Respondents discussed the placement of informative materials in the environment as well as on the Internet. The participants of focus groups determined elevators, staircases, garbage container areas and public transport as suitable locations for informative materials in the surrounding environment. They suggested that it would be also useful to place informative materials in the working environment:

"That's my view of where people spend most of their time. Work, workplace, working environment. And that's about it. (...) Start with those places. And they are the places where you can change your habits in the long term".

Regarding Internet, the availability of informative materials was described as the most important factor. Many participants of focus groups mentioned that the materials available on the Internet are difficult to access. The idea of disseminating informative materials through social networks was considered. But in this case, the participants emphasized that information will be distributed only in that case if it has an attention-catching idea or it triggers an emotional response: 
"About posting it on Facebook, you really have to think of something that attracts attention, because there is a lot of advertisement".

"If it really grabs the emotions and the attention, then you just share, and it reaches many people."

\subsubsection{Applications for smartphones.}

As a possible solution of promoting environmental education and reducing the lack of information, an informative application for smartphones was mentioned. Respondents indicated that a smartphone application might be a quick and easy way to receive reliable information. The possibility of using such applications was discussed in relation to chemical product labelling and chemical product composition, as well as waste sorting aspects:

"The same is about chemicals, if there would be such a trivial application, we all use those smartphones. (...) And to explain these trivial things in a simplified way. I think it would be enough if it explains, for example, the same chemical labelling. If there is a dead fish (symbol), then it is worse than if there is a triangle. Because a lot of people don't even know such things".

\subsubsection{Advertisement and social campaigns.}

The participants of the focus groups discussed the influence of advertisement on people's actions and choices. It was mentioned that advertisement can create a false impression of the norm and set a wrong example, especially in the use of chemicals. Respondents admitted that their actions were influenced by advertisements of washing and cleaning products, as well as the choice of chemical agents and their usage aspects, especially dosage. Certain advertisements can affect consumption and create a need for absolute purity - "sterility". This promotes the excessive use of chemicals, which negatively affects health, household wastewater quality and has an impact on the environment.

"We use chemicals unnecessarily; we don't need some of them at all - not for our skin, not for our hair, but just so someone could earn on this. (...) I think, it's separate science, a whole topic about cosmetics advertisement. (...)"

"Television advertisement shows you pouring from a bottle into a stopper, from the stopper - in the washing machine. This stopper is twice more the amount you need. Or the same with toothpaste: toothpaste is squeezed along almost throughout all of the toothbrush".

The respondents mentioned that advertisement and social campaigns can be used for society education in environmental topics, but in this way only a certain target audience could be reached. If the campaign has succeeded, it can make you evaluate your actions or choices and encourage you to change your habits or actions. Respondents admitted that advertising and social campaigns could be effective if it highlights the health effects of the wrong behavior. As a positive example of the impact of advertisement, respondents mentioned joint-stock companies of "Cẹ̣u satiksmes drošības direkcija" (hereafter CSDD) social campaigns:

"Of course, an advertisement in the mass media. For example, CSDD (...). Their advertisement, they just enter the nation. Why the same can't be done?"

On the other hand, a different view was expressed on the restrictions on use of advertisement and social campaigns for public environmental education. In order for the 
advertisement to give the desired effect and change people's behaviour, it is required that infrastructure or service is available:

"But again, the (advertising) campaign itself won't change anything unless the same system changes, improves. You can advertise as much as you want, but if the person doesn't have the (waste sorting) container, he doesn't. He might feel even more offended, like, "What do you want from me?"

\subsection{Suggested Solutions for Infrastructure Provision and Lack of Services}

Speaking of the possible solutions for infrastructure provision and access to services, the focus group participants identified two key solutions: the implementation of a packaging deposit system and provision of appropriate infrastructure or service. Each of them are considered separately.

\subsubsection{A provision of infrastructure or service.}

The respondents in all of the focus groups mentioned appropriate infrastructure (specialized waste sorting containers) or service (the provision of an appropriate service by the waste manager) provision as the main factor that determines the motivation for waste sorting. All focus groups mentioned this factor as being very important and even decisive for waste sorting.

"If it was assessable (to sort waste), I think that much more people would do it. It is not difficult to put a glass jar in a separate bag”.

"One of the things I really try to do is to sort glass, cardboard and sometimes also plastic. And for our yard, for several block houses, the number of waste containers was reduced. At the beginning we had a whole group of containers for two houses, and now we have the same group on four or six houses, they are emptied at the same frequency or even less frequently. And we have a result that most of the week those containers are full. If I do sort the waste, where should I leave it?"

"Must I really search of a place for waste sorting? Because it was somewhere for a moment, then again it isn't. (...)I really think if it (the container) was somewhere closer to home, it would be much easier for me to persuade everyone else to do such simple things".

However, a part of the respondents (mainly those living in private houses) are more motivated and do waste sorting despite the fact that this service is not provided by waste management company. They export sorted waste to the waste sorting fields. These respondents also expressed their dislike of the waste sorting service available at waste sorting fields:

"I sort waste at home. I have the possibility to sort glass, plastic and cardboard at home, (...) so I collect them (fractions). And then I transport them, (...) to the landfill. So, I go to the landfill and there it begins: "You know, boy, we can't sort this out". Because I have put it all in one bag at home, they put it on the sorting line. I put cardboard, all what is allowed, paper, tetrapacks. I go to the landfill and there: "You know, this one can't be thrown here because you must put it in that container, but this you must put in the other container", so, you have to sort it all one more time. (...) The principle is that I can't only transport the waste and give it to them. No, I have to sit down and do the waste sorting again. Interesting system". 


\subsubsection{Packaging deposit system.}

The offered solution of waste sorting problem and motivation to start sorting waste could be the implementation of packaging deposit system. The respondents support the packaging deposit system implementation and they mentioned that this system could motivate a lot of people to start waste sorting, especially social groups with lower income. Respondents also expressed the view that the implementation of a packaging deposit system could also partially reduce environmental pollution problems by reducing waste.

"I find it very motivating when you just can hand over plastic or glass bottle and get some money. (...) And, for example, if there are those people who are not so conscientious and who will throw bottles in the common trash bag, then (...) those people whose only form of income is to pick up the bottles and so, they will do that. They will do that and earn money - very beautiful".

Some doubts on the implementation of a packaging deposit system were expressed as well. A respondent thought that it would put a strain on socially vulnerable groups, such as seniors:

"My grandmother's pension is 270 euros and she will feel it. I won't feel it (the implementation of deposit system), but she will, and I think, this will be a little problem. (...) Because she counts every cent. I doubt she will carry a whole bag of trash to the shop to transfer to the deposit system".

Another opinion stated that seniors are a group of people that have experienced a successful waste sorting system and therefore are more likely to participate also in packaging deposit system:

"I think this is not a problem for the older generation. In Soviet times everyone did that (waste sorting). The wastepaper was handed over, the empty bottles and the metals were handed over too. The Soviet system was all worked out and so I think for the older generation it should not be such a big problem".

\section{Discussion AND CONCLUSION}

Environmental awareness has been a subject discussed before [16], [19], [20]. Our results show that people feel that their lack of environmental awareness is the cause of their environmentally unfriendly decisions and actions. Education, family status and age are positively related to environmental knowledge [2], [16], [17], meaning that people who are older and more educated are more environmentally aware, which confirms our findings. The young generation is believed to have the power to impact policies and future decisions [21], and previous studies show that they are motivated and solution-driven towards environmental issue management [19], [22], however, in our study all of the respondents in students group did not do waste sorting because the infrastructure was not assessable, which contradicts the results of other studies where students and young people are the most environmentally conscious group. In our study respondents who live in houses, were extra motivated to sort their waste, collect it at their houses and then bring them to the sorting fields. This calls for more research to find out whether environmental behaviour differs between people with different accommodation type. 
The attitudes, knowledge and opinions about environmental issues have been studied before [16], [19], [22], as well as the most effective ways of tackling them [4]. Investing in research and development to find technological solutions (35\%) and introducing heavier fines for breaches of environmental legislation $(34 \%)$ are mentioned as the top two options by Europeans, while "providing more information" ranks as the fifth $(28 \%)$. The role of an individual for environmental protection such as waste recycling or cutting down on single use plastic, buying more local products, cutting down on energy and water consumption is an important indicator of public readiness for environmental problem management. $76 \%$ of respondents from Latvia agree that they as individuals can play a role in protecting their country`s environment, which ranks as one of the lowest in Europe [20].

The information that promotes potential solutions to overcoming environmental issues can trigger a pro-active behaviour rather than messages that just stress the importance and the weight of the problems therefore the information frame that is being delivered to public, must include some doable solutions. It is also studied that the frame of information plays a crucial role in whether or not an action will follow after the information reaches a person. Socio-economic factors influence this greatly [23]. This goes hand in hand with our results, since respondents expressed that the information must be tailored to their needs - it must draw attention, give emotions and make them evaluate their behaviour. The low level of information, the misunderstanding of it and lack of knowledge indicates the need of an efficient information provision strategy. In a study on exploring energy-efficient household product buying out of all studied influencing factors, it was concluded that knowledge has the strongest impact on buying intention $(\beta=0.486$; $p$-value $<0.001)[24]$, which emphasises the importance of knowledge.

The results of current research show that the lack of information is an actual problem not only regarding environmental aspects, but regarding chemicals in households too. Respondents have noticed that information about chemical product's composition and labelling is difficult to understand and is complicated. Other researches showed that available information can influence the choice of households' chemicals and people without specific education have lack of knowledge about labelling of chemical products [25], [26].

One of the main topics that emerged was regarding waste management and recycling. Growing amount of waste is seen as the most important environmental issue in Latvia, based on the data of "Parlemeter of 2019" [21], which aligns closely with opinions expressed in focus group interviews. People that are dissatisfied with the waste management system in their area are more likely to suggest governmental involvement as a solution to these problems [27] - and since the perceived role of an individual for environmental protection in Latvia is one of the lowest in European Union [20], also in our case people are not willing to do more as individuals rather they expect the government to manage the issues regarding waste management and recycling issues.

Access to services surely is important and affects people's behaviour. Respondents that have the opportunity to recycle (have bins near their homes) are more likely to do so. Studies show that infrastructure plays an important role in shaping environmental behaviour and if investments in infrastructure are made, individual environmental behaviour greatly changes [17]. This is also true in our case, since respondents expressed that they would recycle if waste sorting bins would be in their near surroundings.

An application for smartphones was mentioned as a good way for the user to access information about the composition, dosage and other information on the chemical product. An application is made by EU LIFE project "AskREACH" called "Scan4Chem" and currently it is in the process of implementation and is expected to be translated in Latvia as well, but 
the limitation is that "consumer product like toys, clothing, furniture and electronics can be checked for SVHCs in them. Product groups that have an ingredient list, like food, cosmetics and household chemicals are not covered by REACH Art. 33" [28] meaning that this app resolves the issue only partly. Our respondents noted that an app would be a great way to get information on everyday products, as well as cosmetics and even recycling suggestions/tips.

Another research was conducted in United Kingdom in 2010 [29]. The research described people's behaviour of waste sorting in households and focused on factors that complicate waste sorting. The results showed that one of these factors was time and effort and it was determined as important factors to make people continue waste sorting [29]. In the current study the results have been similar: respondents have mentioned a simplicity as a factor that usually determine people's actions and behaviour according to waste sorting. If respondents needed to do some additional activities to manage waste sorting in household, they were more likely to stop sorting, but if the required infrastructure was available, the respondents were more likely to continue waste sorting.

The results of current research present that lack of information and environmental education, as well as availability of relevant infrastructure or service was determined by respondents as the main problems regarding chemical pollution and environmental management. The similar results were obtained in another research, where simplicity, convenience and information were determined as important factors for waste management behaviour in households [30].

Easily assessable, simple and trusted information resources are necessary to clarify properties, usage, storage and destruction of households' chemicals. Increased awareness of public regarding household chemical usage and appropriate and available education for different public groups is essential too. The collaboration between representatives from science, educational system (universities, schools), governmental institutions (ministries, agencies, etc.) and non-governmental organisations is needed to increase public awareness regarding environmental issues with focus to inappropriate chemical usage and consequences that follow. It should be mentioned that the exploration of other environmental factors, for example, indoor air, could offer more value and can be considered as a topic for future research.

\section{ACKNOWLEDGEMENT}

This work has been supported by Rīga Stradiňš University grant for the Institute for Occupational Safety and Environmental Health within the project "Exploring Causes, Effects and Possible Solutions for Chemical Pollution in the Environment: Citizens' and Experts' Views"

\section{REFERENCES}

[1] Miller T. G., Spoolman E. S. Living in the Environment: Concepts, Connections, and Solutions, $16^{\text {th }}$ edition. Belmont: Brooks/Cole, Cengage Learning, 2009.

[2] European Commission, Directorate-General for Climate Action. Special Eurobarometer 490. Climate change. Brussels: Publications Office of the European Union, 2019.

[3] European Commission, Directorate-General for Internal Market, Industry, Entrepreneurship and SME's. Special Eurobarometer 456. Chemical safety. Brussels: Publications Office of the European Union, 2017.

[4] Weiss T. F., et al. Chemical Pollution in Low- and Middle-income countries. Eawag: Swiss Federal Institute of Aquatic Science and Technology, 2016.

[5] Madu C. N. Environmental Planning and Management. Imperior Collage Press, 2007.

[6] Antweiler W. Elements of Environmental Management. University of Toronto Press: Toronto Buffalo London, 2014. 
[7] Latvian Institute of Aquatic Ecology. Report: Results on Screening of Hazardous Substances in Latvia [Online]. [Assessed: 19.05.2020.]. Available: http://baltacthaz.bef.ee/files/c15/c55/Latvian\%20Screening_ENG.pdf

[8] Cohiba Project Consortium. Major Sources and Flows of the Baltic Sea Action Plan. Hazardous Substances [Online]. [Assessed: 21.05.2020]. Available: https://www.isi.fraunhofer.de/content/dam/isi/dokumente/ccn/2011/COHIBAWP4-Final-report_1.pdf

[9] Fammler H., et al. Hazardous Substance Reduction Potentials in Private Households. Assessment of Household Checks as a Tool for Awareness Raising about Hazardous substances. Hamburg: Baltic Environmental Forum Deutschland, 2019.

[10] Apte K., Salvi S. Household air pollution and its effects on health. F1000 Research $2016: 2593$. https://doi.org/10.12688/f1000research.7552.1

[11] Kubule A., et al. Towards Efficient Waste Management in Latvia: An Empirical Assessment of Waste Composition. Environmental and Climate Technologies 2019:23(2):114-130. https://doi.org/10.2478/rtuect-2019-0059

[12] HBM4EU - Science and Policy for a Healthy Future. https://www.hbm4eu.eu/ (formal communication).

[13] Fammler H., et al. Nonhazcity - A Flagship Project of the Baltic Sea Region [Online]. [Assessed: 22.05.2020.]. Available: https://drive.google.com/file/d/1uB2tv3h1dXdLYSLi1Pwna3PxC0UXSIMo/view

[14] Rīgas pašvaldības bīstamo vielu samazināšanas rīcības plāna projekts (Draft action plan for reduction of hazardous substances of Riga municipality). [Online]. [Assessed: 21.05.2020.]. Available: https://mvd.riga.lv/uploads/nonhazcity/R\%C4\% $\mathrm{ABc} \% \mathrm{C} 4 \% \mathrm{ABbas} \% 20 \mathrm{pl} \% \mathrm{C} 4 \% 81$ na $\% 20$ projekts.docx (in Latvian)

[15] HBM4EU - Science and Policy for a Healthy Future. https://www.hbm4eu.eu/ (formal communication).

[16] Crouch M., McKencie H. The logic of small samples in interview-based qualitative research. Social Science Information 2006:45(4):489-499. https://doi.org/10.1177/0539018406069584

[17] Aminrad Z., Zakaria S. Z. B., Hadi A. S. Influence of Age and Level of Education on Environmental Awareness and Attitude: Case Study on Iranian Students in Malaysian Universities. Medwell Journals 2011:6:15-19. https://doi.org/10.3923/science.2011.15.19

[18] Du Y., et al. Changes in Environmental Awareness and Its Connection to Local Environmental Management in Water Conservation Zones: The Case of Beijing, China. Sustainability 2018:10(6):2087. https://doi.org/10.3390/su10062087

[19] Guest G., Bunce A., Johnson L. How Many Interviews Are Enough? An Experiment with Data Saturation and Variability. Field Methods 2006:18(1):59-82. https://doi.org/10.1177/1525822X05279903

[20] Padmanabhan J., Mittal K., Borthakur A. Environmental Education and Awareness of Higher Education Students. Journal of International Research in Geographical and Environmental Education 2018:27(3):216-233. https://doi.org/10.1080/10382046.2017.1349375

[21] European Commission, Directorate-General for Environment. Special Eurobarometer 468. Attitudes of European Citizens towards the Environment. Brussels: Publications Office of the European Union, 2017.

[22] European Parliament. 2019 Parlemeter. Focus on Climate Change [Online]. [Assessed 16.02.2020.]. Available: https://www.europarl.europa.eu/resources/library/media/20191129RES67708/20191129RES67708.pdf

[23] Verulava T., et al. Students Population`s Attitude Concerning Environmental Issues in Georgia. Georgian Medical News 2019:9(294):150-155.

[24] Van de Velde L., et al. The Importance of Message Framing for Providing Information about Sustainability and Environmental Aspects of Energy. Energy Policy 2010:38(10):5541-5549. https://doi.org/10.1016/j.enpol.2010.04.053

[25] Alam S. S., et al. Factors Affecting Energy-Efficient Household Products Buying Intention: Empirical Study. Environmental and Climate Technologies 2019:23(1):84-97.https://doi.org/10.2478/rtuect-2019-0006

[26] Glegg G. A., Richards J. P. Chemicals in Household Products: Problems with Solutions. Environmental management 2007:40(6):889-901. https://doi.org/10.1007/s00267-007-9022-1

[27] Su T.-S., Hsu I-Y. Perception towards chemical labeling for college students in Taiwan using Globally Harmonized System. Safety Science 2008:46(9):1385-1392. https://doi.org/10.1016/j.ssci.2007.09.002

[28] Cheng C., Urpelainen J. Who should take the garbage out? Public opinion on Waste Management in Dar es Salaam, Tanzania. Habitat International 2015:46:111-118. https://doi.org/10.1016/J.HABITATINT.2014.11.001

[29] SCAN4CHEM App for Checking Substances of Very High Concern in Products Launched. [Online]. [Assessed: 25.05.2020.]. Available: https://www.askreach.eu/scan4chem-app-for-checking-substances-of-very-high-concern-inproducts-launched/

[30] Tucker P., Speirs D. Attitudes and Behavioural Change in Household Waste Management Behaviours. Journal of Environmental Planning and Management 2003:46(2):289-307. https://doi.org/10.1080/0964056032000070927

[31] Miafodzyeva S., Brandt N. Recycling Behaviour among Householders: Synthesizing Determinants via a Meta-analysis. Waste and Biomass Valorization 2013:4:221-235. https://doi.org/10.1007/s12649-012-9144-4 